\title{
Diachrone und synchrone Aspekte von Personal-, Possessiv- und Demonstrativpronomina in der Slawia
}

\author{
ARNO WONISCH \\ Institut für Slawistik, Karl-Franzens-Universität Graz, Merangasse 70, \\ A-8010Graz,arno.wonisch@uni-graz.at
}

\begin{abstract}
Namen prispevka je prikazati nekatere podobnosti in razlike $\mathrm{v}$ sistemu osebnih, svojilnih in kazalnih zaimkov v stari cerkveni slovanščini in v današnjih slovanskih jezikih. Po kratkem uvodu s splošnimi podatki o poimenovanju te besedne vrste $\mathrm{v}$ slovanskih jezikih sledi krajša analiza navedenih zaimenskih kategorij z diahronega in s sinhronega vidika. Na ravni zaimkov je opozorjeno tudi na nekatere posebnosti v odnosu med prvim slovanskim knjižnim jezikom in sodobnimi jeziki slovanske jezikovne družine.
\end{abstract}

The aim of this article is to identify relevant correspondence, similarities and differences in the system of personal, possessive and demonstrative pronouns in Old Church Slavic and the present Slavic languages. After the first part, which is devoted to some general aspects of the nomination of pronouns in the languages in question, it is continued with the analysis of the mentioned kinds of pronouns on the diachronic and synchronic level, which is proceeded with the description of some mentionable aspects in pronominal systems in the first Slavic literary language and in the present-day languages.

Ključne besede: osebni, svojilni, kazalni zaimki, slovanski jeziki, stara cerkvena slovanščina

Key words: personal pronouns, possessive pronouns, demonstrative pronouns, Slavic languages, Old Church Slavic

In vorliegendem Beitrag werden ausgewählte Charakteristiken pronominaler Lautungen in den heutigen slawischen Sprachen betrachtet und in einen Kontext zu ihren Vorläuferinnen im Altkirchenslawischen gesetzt. Dabei werden nach einleitenden terminologischen Angaben die Darstellungen gemäß einer 
funktionalen Einteilung dieser Wortart in Personal-, Possessiv- und Demonstrativpronomina vorgenommen, wobei ein Schwerpunkt der Ausführungen auf der südslawischen Pronominallandschaft liegt.

Betrachtet man eingangs die terminologischen Bezeichnungen dieser Wortart in der Slawia, so lässt sich erkennen, dass eine (quantitativ ungleiche) Nomination vorliegt, indem die Mehrzahl der Sprachen bei der Benennung der hier behandelten Wortart eine direkte semantische Übernahme des lateinischen Begriffs Pronomen vornimmt. Hierbei wird mit dem Präfix za-der Möglichkeit des „Für-etwas-eintreten-Könnens“ Ausdruck verliehen, wie es neben Bosnisch/Kroatisch/Montenegrinisch/Serbisch (zam/j/enica $)^{1}$ auch im Mazedonischen (заменка), Polnischen (zaimek), Slowakischen (zámeno), Slowenischen (zaimek), Tschechischen (zájmeno), Ukrainischen (займенник) und Weißrussischen (займеннік) der Fall ist. Mit diesen Bezeichnungen korreliert im Bulgarischen und Russischen местоимение sowie im Rusinischen містоназывник, indem eine Fokussierung auf das „Ersetzen-Können“ (место- bzw. місто- in der Bedeutung ,anstelle') zum Ausdruck gebracht wird. Die beiden sorbischen Sprachen bilden hierbei eine Ausnahme, indem das Obersorbische neben (dem wohl durch das Deutsche motivierte) pronomen auch das slawische naměstnik (in der Bedeutung von ,Stellvertreter') kennt, mit dem auf niedersorbischer Seite einzig der Begriff pronomen korreliert. Im Allgemeinen kann für Pronomina festgehalten werden, dass sie sich durch scheinbar gegensätzliche Eigenschaften definieren lassen, indem mehreren nach Ganzheitlichkeit strebenden Benennungsversuchen eine kleine und kompakte bzw. unveränderliche Gruppe von Wörtern gegenübersteht. Diese Abgeschlossenheit nach außen geht mit einer ausgeprägten morphologischen und semantischen Heterogenität und Differenzierung im Inneren einher. ${ }^{2}$

\footnotetext{
${ }^{1}$ In terminologischer Hinsicht trifft man im Rahmen des Bosnischen, Kroatischen, Serbischen (und auch Montenegrinischen; im Folgenden werden diese vier Sprachen auf neuštokavischer Basis auch als $\mathrm{B} / \mathrm{K} / \mathrm{M} / \mathrm{S}$ bezeichnet) in der bosnischen Grammatik von Jahić/Halilović/Palić 2000 (245) neben zamjemice auch auf den Begriff upućenice, der im Besonderen die verweisende Funktion von Pronomina (uputiti =,/ver-, hin-/weisen, zeigen'; auch: ,senden') herausstreichen soll.

${ }^{2}$ Bezüglich der Abgeschlossenheit der Wortart der Pronomina vgl. Schulz/Griesbach (1978), wo für die deutsche Sprache davon gesprochen wird, dass der „Bestand an Pronomen“ [sic] fest und „,nicht mehr erweiterungsfähig /.../“ sei. Gleichzeitig wird auch analog zu den Grammatiken anderer Sprachen auf den „verhältnismäßig reichen Bestand an Flexionsformen“ verwiesen (Schulz/Griesbach 1978: 150). In Babić et al. (1991) ist in Bezug auf die Anzahl die Rede von rund 100 unterschiedlichen Pronomina im Kroatischen, deren Bestand unverändert bleibe und sich nicht vergrößere (Babić et al. 1991: 646).
} 


\section{Personalpronomina}

Im Vergleich zu den slawischen Gegenwartssprachen weist die älteste slawische Schriftsprache, das Altkirchenslawische, bei den Personalpronomina zwei wesentliche differenzierende Aspekte auf, die sich im Vorhandensein des Duals und im Fehlen von „klassischen“ pronominalen Formen für die 3. Person äußern, an deren Stelle die anaphorischen Pronomina distalen (d. h. auf größere

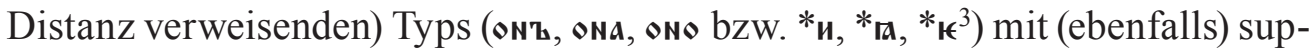
pletivem Stammwechsel ${ }^{4}$ standen. Ein augenscheinlicher Unterschied zwischen der Sprache Kyrills und Methods und der Mehrzahl der slawischen Sprachen

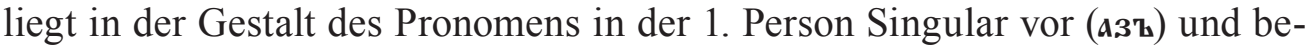
trifft zum einen die Opposition zwischen konsonantischem und vokalischem Auslaut und zum anderen die Existenz bzw. das Fehlen der $i$-Prothese. Bei einer Gegenüberstellung nach dem Auslaut wird eine innere territoriale Gliederung offenbar, im Rahmen derer sich in Abhängigkeit von konsonantischer Archaizität und vokalischer Innovation zwei Gruppen differenzieren lassen: Während die Ost- und Westslawia durchgehend vokalische Endungen auf $-a^{5}$ aufweisen, stellt sich die Lage innerhalb der Südslawia komplexer dar, weil hier eine areale Opposition zwischen nördlicher und südlicher Peripherie einer- und dem von $\mathrm{B} / \mathrm{K} / \mathrm{M} / \mathrm{S}$ gebildeten südslawischen Zentralraum andererseits vorliegt. So zeichnen sich bezüglich der standardologischen Lösungen das Bulgarische und Mazedonische als ostsüdslawische Sprachen und das Slowenische als nördlichste Sprache dieses Areals durch Bewahrung der konsonantischen Endung aus (Bulgarisch: a3, Mazedonisch: jac, Slowenisch: jaz). ${ }^{6}$ „Unterhalb“ der Ebene des Standards lässt sich jedoch auch innerhalb des B/K/M/S-Sprachraumes ein (marginales und unter dem Einfluss des Štokavischen möglicherweise in Zukunft schwindendes) Bewahren konsonantischer Endungen feststellen, wie es etwa in den kajkavischen Dialekten von Bednja (im kroatischen Zagorje), Varaždin (jeweils joz - neben jo - mit geänderter Vokalqualität) und in der Region Gorski Kotar (est, wohl mit Anlehnung an die angrenzenden slowenischen Dialekte) der Fall ist (vgl. Wonisch 2000: 16-21). Auslautendes -z bzw. -s liegt daneben auch noch in Teilen des nördlichen čakavischen Dialektareals vor, wo

\footnotetext{
${ }^{3}$ Bei diesen drei Formen handelt es sich um theoretische Konstruktionen durch Wegnahme des Suffixes -жє, das unter anderem zur Bildung der Relativpronomina ижє, гажє und єжє herangezogen wurde.

${ }^{4}$ Dieser Suppletivismus lässt sich in vielen Sprachen der Welt erkennen, so etwa in den Sprachen des Kaukasus (vgl. Majtinskaja 2009: 192), in besonderem Ausmaß jedoch auch in indoeuropäischen Sprachen wie im Englischen, Spanischen, Französischen, Dänischen u. a., in denen Personalpronomina über größere Flexionsvarianz als Substantive verfügen. Vgl. dazu z. B. im Englischen he, him, im Französischen il, lui, le und im Spanischen ella, le, la, denen kasuslose Substantivparadigmata gegenüberstehen.

${ }^{5}$ Isolierte Phoneme und unter der Wortebene angesiedelte Buchstabenkombinationen werden mit Hinweis auf ihre Position in einem Wort mit einem Viertelgeviertstrich versehen (z. B.: $-a,-a$ - oder $-a$-).

${ }^{6}$ Diese wird ungeachtet der orthographischen Lösungen stets stimmlos realisiert.
} 
etwa für Zentralistrien neben jã auch jãs erfasst wurde. ${ }^{7}$ Historisch gesehen kann für den Schwund des ehemaligen konsonantischen Auslauts angenommen werden, dass er das Ergebnis einer Assimilation beim Auftreten eines Sandhi darstellt, indem er in Verbindungen wie *jaz sam oder*jaz znam getilgt wurde (Skok 1971: 741). In akzentueller Hinsicht zeichnet sich $j a \hat{~ i m ~ B / K / M / S ~ d u r c h ~}$ eine Dehnung in Form von lang fallendem Akzent aus, indem wohl der Verlust des Endkonsonanten durch lange Akzentuierung ausgeglichen wurde, sodass heute eine Opposition zu durchwegs kurzem Vokal im Bulgarischen, Mazedonischen und Slowenischen vorliegt. ${ }^{8}$ Zur anlautenden $i$-Prothese kann gesagt werden, dass diese neben dem Altkirchenslawischen einzig im bulgarischen Standard fehlt, wodurch sich eine Kontinuität beginnend mit der ostsüdslawischen Herkunft der ältesten slawischen Standardsprache bis zur Normierung des Bulgarischen in Fortführung und Wahrung der Tradition dieses Raumes erkennen lässt. Auch in (vornehmlich östlichen) Dialekten des Mazedonischen kann anlautendes und im Standard festgeschriebenes $i$ - entfallen. Bedingt durch diese Dualität von in der klaren Mehrzahl der Sprachen stark verankertem $i$ - und ostsüdslawisch-vokalischem Anlaut ( $a$-) kann für das Urslawische eine rekonstruierte konsonantische Form iaz angenommen werden, die möglicherweise ebenfalls Erfordernissen beim Auftreten eines Sandhi entsprach oder zur Hiatusvermeidung diente (vgl. dazu Skok 1971: 471-472).

Bei einer Gegenüberstellung des Altkirchenslawischen mit den heutigen Sprachen erscheint im Paradigma des Singularpronomens der 1. Person auch der Dativ von Interesse, der in seiner endbetonten Langform most den nachmalig reduzierten Wurzelvokal в aufweist. Entsprechend den Regeln für den Ersatz der Jer-Laute hätte ь an dieser Stelle eigentlich schwinden müssen, wie es auch bei mně (Tschechisch), mne (Slowakisch), mnie (Polnisch), mnjo (Niedersorbisch), mпі (Obersorbisch) und мне (Russisch, Weißrussisch) der Fall war bzw. ist. In der gesamten Südslawia und im Ukrainischen sowie Rusinischen hingegen trat im Unterschied dazu und wohl in Analogie zum Wurzelvokal des Genitivs eine Vokalisierung mit $-e$ - ein, die $\mathrm{zu}$ orthotoniertem mene im B/K/M/S, im Bulgarischen, Mazedonischen und Slowenischen sowie zu мені (Ukrainisch) und мени (Rusinisch) führte. Vergleichbares gilt für den Genitiv dieses Pronomens, der ebenfalls eine Gegenüberstellung von ein- ( $m n-)$ und zweisilbigen (men-/мен-/, mјаn- /мян-/) Formen offenbart. In diesem Falle verläuft die Teilung entlang der Grenze zwischen der Ost- und Westslawia, wobei das Russische, Ukrainische, Weißrussische und bedingt das Rusinische (мене vs. мня) die Vokalisierung zwischen den Konsonanten $m$ - und - $n$ - mit

\footnotetext{
${ }^{7}$ Darüber berichtet Janneke Kalsbeek in ihrer Monographie zum Dialekt von Orbanići nahe Žminj (1998: 158). Ähnliches wurde im Raume des Čakavischen auch für die Orte Lovran (jaz) und Tometići bei Kastav (jas) erhoben (Skok 1971: 741). Darüber hinaus wird an zitierter Textpassage auch die Feststellung getroffen, wonach „/.../ stariji ljudi u Liburniji govore jas u samostalnom položaju, inače $j a / . . . / “$.

${ }^{8}$ Vgl. dazu auch die Lautung [jös] mit durch die kurze Artikulation bedingtem Wandel von $[a] \mathrm{zu}[ə]$ (Schwalaut), wie sie in den meisten Dialekten des Slowenischen vorliegt.
} 
der gesamten Südslawia teilen, wogegen in der Westslawia - wohl auf Grund eines Ausgleichs mit den kontrahierten Lautungen von Dativ, Instrumental und Lokativ - kein Wurzelvokal mehr vorhanden ist und die jeweiligen Formen mne (Tschechisch) mňa (Slowakisch), mnie (Polnisch), mnjo (Niedersorbisch) und mnje (Obersorbisch) lauten. ${ }^{9}$ Während im B/K/M/S, im Bulgarischen, Mazedonischen und Slowenischen mепе bzw. мене standardisiert ist, trifft man im Russischen auf меня, im Ukrainischen auf мене und im Weißrussischen auf мяне, wobei die russische Endung auf -mja unikal ist und auf die geschwundenen akkusativischen Enklitika $м я$, тя und $с я$ zurückgeht. Tonlose Formen dieser Art sind im Verband der ostslawischen Sprachen nur mehr für das Rusinische erfasst, das die Lautungen ( $м$ ня (1. Person Genitiv und Akkusativ) und $m я$ (2. Person Genitiv und Akkusativ) kennt, die den historischen ostslawischen Formen entsprechen, wobei (м)ня mit optionalem $\mathcal{M}$ - in Anlehnung an die häufige Konsonantengruppe $\boldsymbol{M H}$ - gebildet wurde. ${ }^{10}$

Neben den Lautungen des Nominativs, Genitivs und Dativs bietet vor allem auch der Instrumental interessante Erkenntnisse über die Innovationsfreudigkeit des $\mathrm{B} / \mathrm{K} / \mathrm{M} / \mathrm{S}$, denn die standardisierten Formen mnom und mnome setzen (in gleichem Maße wie auch die 2. Person mit tobom) diese Sprachen in eine Totalopposition zur gesamten übrigen Slawia, die die Nasalendung des Altkirchenslawischen fortführen. So zeigen menoj, mano ${ }^{11}$ (Slowenisch) mnou (Tschechisch, Slowakisch) mna (Polnisch), мной, мною (Russisch), мною (Ukrainisch) und мной, мною (Weißrussisch) durchgehend vokalischen Auslaut als Ergebnis der seinerzeitigen Endung auf -هı. Die B/K/M/S-Lautung auf - $m$ stellt hingegen eine auf das 15. Jahrhundert zurückgehende Angleichung an das Paradigma der a-Deklination dar, die bedingt durch den Zusammenfall mit der o-Deklination (vgl. jezikom, ženom) zu einem Schwinden von ehemaligen mnoju oder manoju führten (vgl. Leskien 1914: 455-456). Ein Blick in die (im Vergleich zum Standard durchaus archaische) Dialektlandschaft von $\mathrm{B} / \mathrm{K} / \mathrm{M} / \mathrm{S}$ kündet jedoch - erwartungsgemäß - in manchen kajkavischen und

${ }^{9}$ Vgl. dazu die Lautungen in den baltischen Sprachen, wo für das Litauische zweisilbiges manęs (Genitiv) und mane (Akkusativ), für das Lettische manis und mani und für das (im östlichen Lettland beheimatete) Lettgälische mane, mani im Genitiv und mani im Akkusativ gilt. Alle diese drei Sprachen zeigen in den Kasus obliqui durchgehend den Wurzelvokal - $a$-.

${ }^{10}$ Information nach Sydor 2002 (133), der in diesem Zusammenhang die Lexeme мнясо, мняч и. a. nennt, die in dieser Form in der Slawia unikal sind.

${ }^{11}$ Als unikal innerhalb der Slawia kann die zweisilbige Lautung im Slowenischen angesehen werden, die von einem Vokalismus mit zwei Qualitäten zeugt. Hierbei kann -e- in menoj wohl in Analogie zum übrigen Paradigma gesehen werden, das einen Ausgleich gemäß der Genitivlautung herstellte. Die in allen Werken sekundär genannte Form mano hingegen lässt sich am ehesten als nordsüdslawischen a-Vokalismus erklären, der auch in den nahe gelegenen kajkavischen und čakavischen Dialekten angetroffen wird, wo ebenfalls Formen mit - $a$ - erhoben wurden (so etwa manu bei Jedvaj 1956: 306 und manon bei Kalsbeek 1998: 162 u. a.). Auf diese Weise liegt an der südslawischen Peripherie eine Isoglosse vor, die einen Wandel von $\mathbf{z}>a$ auch in ehemals schwacher Position zeigt. 
(nördlichen) čakavischen Idiomen noch von der Existenz von Formen des Typs mano, manu u. a., ${ }^{12}$ die einen Beleg für die Existenz der älteren Gestalt $\mathrm{im} \mathrm{B} / \mathrm{K} / \mathrm{M} / \mathrm{S}$ liefern.

\section{Possessivpronomina}

Im Rahmen der Klasse der Possessivpronomina möge eingangs ein Verweis auf die altkirchenslawischen Lautungen мои, мога, мок und машь, маша, маше ergehen, die dem weichen Deklinationsmuster folgen. Das Entstehen dieser pronominalen Formen basiert auf einer Verschmelzung der possessiven Suffixe *ib, *ia, *ie mit dem Stamm der Kasus obliqui der Personalpronomina der 1. und 2. Person (Singular wie Plural), die zu Lautungen entsprechend der Stämme $m$-, $t$ - (Singular) und $n$-, $v$ - (Plural) führten. ${ }^{13}$ Für Sprechende südslawischer Sprachen mag es bemerkenswert erscheinen, dass das auf südslawischer Basis entstandene Altkirchenslawische kein Possessivpronomen für die 3. Person kannte. Diese Funktion wurde in der ältesten slawischen Schriftsprache von genitivischen Formen der entsprechenden Personalpronomina übernommen, die in meist postpositiver Position auf Besitzzugehörigkeiten verwiesen und zur Verstärkung vielfach auch um das anknüpfende Partikel -жє erweitert werden konnten, vgl. dazu die neutestamentlichen Beispiele оүчитекь его (Lk

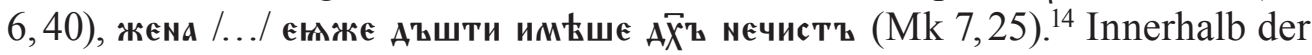
gegenwärtigen Slawia zeichnet sich auch einzig der Süden durch vollständige Paradigmata für die 3. Person aus, wogegen das Ost- und Westslawische (vergleichbar dem Altkirchenslawischen) genitivische und nunmehr unveränderliche Formen gebrauchen, von denen zwei auf den Singular (eine für Maskulinum und Neutrum, die zweite für das Femininum) und eine auf den Plural entfallen. So etwa stehen его брат (Russisch), його брат (Ukrainisch), яго брат (Weißrussisch), jeho bratr (Tschechisch), jeho brat (Slowakisch), jego brat (Polnisch), jogo bratš (Niedersorbisch) und jeho bratr (Obersorbisch) auf südslawischer Seite njegov brat (B/K/M/S, Slowenisch), негов(ият) брат (Bulgarisch) und негов(иот) брат (Mazedonisch) gegenüber, wobei B/K/M/S und Slowenisch

\footnotetext{
${ }^{12}$ Letztere der beiden Formen wurde auf der Kvarnerinsel Susak angetroffen, die sich bedingt durch ihre Abgeschiedenheit als besondere Bewahrerin alter Lautungen erweist. Davon zeugt unter anderem auch die Akzentuierung dieser Pronominallautung mit dem čakavischen Akut (mãnu). Vgl. dazu Wonisch 2000: 40-41.

${ }^{13}$ Genaueres zu dieser Genese siehe in Duridanov 1991: 240-241, Gluhak 1993: 419 und Skok 1971: 449. Insgesamt gesehen kann im Besonderen für die 1. und 2. Person dieses Pronomens in den indoeuropäischen Sprachen ein hohes Maß an Ähnlichkeit ausgemacht werden, das vor allem durch den possessiven Anlaut $m$-, $t$ - (im Singular) sowie $n$ - und $v$-zum Ausdruck kommt.

${ }^{14}$ Abkürzungen für die Evangelien nach Lukas und Markus mit zugehöriger Kapitel- und Versnummer.
} 
über vollständige adjektivische Paradigmata verfügen. ${ }^{15}$ In Weiterführung dieser typologischen Differenzierung der drei slawischen Großareale, die wie bei vielen anderen Aspekten auch - eine Opposition Ost- und West- vs. Südslawia erkennen lässt, sei ein Blick auf die maskuline und neutrale Form des Pronomens im Genitiv Singular geworfen, die im Altkirchenslawischen die Gestalt moюro besaß. ${ }^{16}$ Dies erscheint deshalb erwähnenswert, weil der Endungsvokal innerhalb der heutigen Slawia ebenfalls arealbildend wirkt, indem er den Süden wiederum vom Osten und Westen differenziert. So wird im $\mathrm{B} / \mathrm{K} / \mathrm{M} / \mathrm{S}$ (neben konsonantischem mojeg und kontrahiertem mog) mojega bzw. moga angetroffen, wobei mojega auch die einzige Lautung im Slowenischen darstellt. ${ }^{17}$ Im Unterschied dazu weisen die ost- und westslawischen Sprachen stets auslautenden o-Vokalismus auf, vgl. dazu моего (Russisch), моєго (Ukrainisch), майго (Weißrussisch), mého (Tschechisch, Slowakisch), mojego (Polnisch), mójogo (Niedersorbisch) und mojeho (Obersorbisch). Dazu kann ergänzt werden, dass B/K/M/S und Slowenisch die in der nördlich-peripheren (trifft auf Slowenisch und das Kajkavische und Čakavische zu) und zentralen Südslawia (das Štokavische) übliche Genitivendung auf - $a$ besitzen, die auch in den anderen pronominalen und in den adjektivischen Paradigmata vertreten ist.

Abschließend kann für eine kontrastive Untersuchung der Possessivpronomen im Altkirchenslawischen und in den heutigen Sprachen gesagt werden, dass sich innerhalb der Slawia die südslawischen Sprachen im Unterschied zu den anderen beiden Arealen durch einen reicheren Formenbestand auszeichnen, der sich in der Präsenz lückenloser Paradigmata der Possessivpronomina in der 3. Person manifestiert.

\section{Demonstrativpronomina}

Im Unterschied zur durchaus überschaubaren Zahl an Personal- und Possessivpronomina, die hinsichtlich Quantität und Bedeutungsumfang in den indoeuropäischen Sprachen nur geringfügige Abweichungen aufweisen, betritt man mit den Demonstrativpronomina ein weites Feld, als dessen elementare Charakteristik deiktische Graduierungen von Nähe und Ferne bezeichnet werden können. Viele der in der Sprache Kyrill und Methods vorhandenen Formen sind in der heutigen Slawia jedoch nicht mehr anzutreffen, wobei im Altkirchensla-

${ }^{15}$ Im Bulgarischen und Mazedonischen werden auf Grund des Verlustes der Nominaldeklination nicht die Kasus-, wohl aber die Genus- und Numeruskategorie der hier behandelten Possessiva differenziert.

${ }^{16}$ Die in Folge getroffenen Ausführungen treffen gleichermaßen auch auf die 2. Person (твокег) und das Reflexivum (свокге) zu.

${ }^{17}$ Bulgarisch und Mazedonisch können auf Grund des Kasusverlustes hier nicht in die Analyse einbezogen werden, weil die einzig möglichen Formen мой (Kasus rectus und Kasus obliqui, unbestimmt), моят (Kasus rectus, bestimmt), моя (Kasus obliqui, bestimmt) bzw. мој (alle Kasus, unbestimmt) und мojom (alle Kasus, bestimmt) lauten. 
wischen folgende grundlegenden Demonstrativpronomina existieren: $\mathbf{T} \mathbf{k}, \mathbf{T a}$, то; опъ, ома, оно; овъ, ова, ово иnd сь, си, сє. Diese zeichnen sich durch eine Gliederung nach den universalen pronominalen Stämmen $t b^{-}, o v b-$, onz- (hart) und $s b$ - (weich) aus, die - $S b$ - ausgenommen - auch in den meisten Gegenwartssprachen zur Bildung von Demonstrativa herangezogen und nach hartem und weichem Stamm dekliniert werden. ${ }^{18}$ Ausgehend von diesem Grundbestand kennt das Altkirchenslawische mehrere mit - $k$ - verlängerte Formen, von denen folgende genannt seien: так'ъ, така, такө (medial, d. h. auf mittlere Distanz verweisend), овакъ, овака, овакө (proximal, d. h. auf nahe Distanz verweisend), онакъ, онака, онакө (distal), такөвъ, такөва, такөво (medial) ${ }^{19}$, сикъ, сика, сико (proximal), сицеь, сицева, сице (proximal), селикъ, селика, секико (proximal) und төликъ, төлика, төликө (medial). Bei den mit s-Stamm gebildeten, weichen Demonstrativpronomina lagen im Altkirchenslawischen neben den Grundformen $\mathbf{c} \mathbf{b}, \mathbf{c} \mathbf{n}, \mathbf{c} \in$ auch die mit suffixalem (palatalem) -c-erweiterten сиць, сица, сице (proximal) vor. Diesbezüglich lässt sich eine Parallelität zu $\mathrm{B} / \mathrm{K} / \mathrm{M} / \mathrm{S}$ erkennen, denn wie auch das Altkirchenslawische zeichnen sich die Nachfolgesprachen des Serbokroatischen bzw. Kroatoserbischen durch eine dreifache Ausdrucksmöglichkeit von Graden der Entfernung aus, die durch die Demonstrativa ovaj, ova, ovo; taj, ta, to und onaj, ona, ono zum Ausdruck gebracht werden können. ${ }^{20}$ Der bereits aus dem Altkirchenslawischen bekannte (harte) Stamm ovъ- übernahm dabei die Funktion von heute kaum bzw. nicht mehr vorhandenen sb-, während die Bedeutungen der Formen mit anlautendem $t b$ - und $o n b$ - weitergeführt wurden.

In der Südslawia verbleibend sei nun ein Blick auf die beiden ostsüdslawischen Sprachen Bulgarisch und Mazedonisch geworfen, die trotz ihrer engen Verwandtschaft ein unterschiedliches System besitzen. Während das Mazedonische mit B/K/M/S in quantitativer Hinsicht konform geht und eine dreifache Deixis in der Gestalt von овој, тој und оној aufweist, wird das Bulgarische von einem Dualismus gekennzeichnet, im Rahmen dessen този für Nähe steht und онзи auf eine größere Entfernung hinweist. ${ }^{21}$ Das Slowenische an der nördlichen Peripherie der Südslawia weist das System des B/K/M/S und

${ }^{18}$ In der heutigen Slawia werden ganzheitlich erhaltene Paradigmata mit dem Pronominalstamm $s b$ - nicht mehr angetroffen. Umfassendes zu Etymologie und einzelsprachlicher Vertretung dieser universalen Stämme siehe in Miklosich 1926.

${ }^{19}$ Dieses Pronomen verfügt auch über eine adjektivische Langform des Tурь такөвъи.

${ }^{20}$ Einhergehend damit bieten $\mathrm{B} / \mathrm{K} / \mathrm{M} / \mathrm{S}$ auch dreigliedrige Adverbien zur Beschreibung lokaler Verhältnisse, die - in Abhängigkeit von der Position bzw. von der Bewegungsrichtung - durch eine fünfgliedrige Reihe zum Ausdruck gebracht werden können: ovdje, tu, ondje - odavde, odatle, odande - ovamo, tamo, onamo - ovuda, tuda, onuda-dovde, dotle, donde.

${ }^{21}$ Sowohl този als auch онзи gehen auf die entsprechenden und bereits besprochenen Stämme zurück und wurden mit dem Intensivierungspartikel - $3 u$ verlängert. 
des Mazedonischen auf, indem mit $t a^{22}-t i s t i-o n^{23}$ auf Seiten von B/K/M/S ovaj-taj-onaj korrespondieren. Der semantische Wert dieser jeweils dreigliedrigen Pronominalkette kann im Falle von ta - tisti bzw. ovaj - taj (mit proximaler bzw. medialer Bedeutung) als annähernd gleich bezeichnet werden kann, indem die Formen ta bzw. ovaj auf Nähe, tisti bzw. taj auf Medialität und oni bzw. onaj auf Ferne verweisen. Bei oni bzw. onaj liegt hingegen ein Unterschied vor, indem oni über die Bezeichnung kazalni nedoločni zaimek verfügt, dem eine mitunter pejorative und in vielen Fällen auch archaische Bedeutung zukommt. Im Rahmen der Ostslawia, deren Sprachen ebenso wie Bulgarisch und Mazedonisch bei den Pluralformen der Demonstrativa keine Genera unterscheiden, greifen Russisch, Ukrainisch und Weißrussisch auf ein zweigliedrig-deiktisches System zurück, während das Rusinische breitere Möglichkeiten bietet. Generell kann eine Differenzierung zwischen dem Russischen und Weißrussischen auf der einen und dem Ukrainischen und Rusinischen auf der anderen Seite ausgemacht werden, die sich in einer stärkeren Archaizität und feineren Ausdrucksoptionen in den beiden eng verwandten Sprachen auf dem Staatsgebiet der Ukraine manifestiert. Während für den Standard des Russischen und Weißrussischen heute nur auf эmom, mom (Russisch) ${ }^{24}$ und гэты, той (Weißrussisch) verwiesen wird, verfügt das Ukrainische neben den semantisch analogen Formen uуей und той weiters über verstärkendes оиеци und altkirchenslawisches Erbe tradierendes ceŭ, das in Regelwerken sekundär genannt und als veraltet ausgewiesen wird. ${ }^{25}$ Das Rusinische besitzt neben weichem сись und hartem mom zum Ausdruck der grundlegenden ostslawischen Zweifachdeixis weiters die Lautungen гевтот (vgl. гэты im Weißrussischen), aнmom usw., die vom prinzipiell gut ausgebauten Pronominalsystem dieser Sprache zeugen. ${ }^{26}$

Ausgehend vom Rusinischen und von dem im Vergleich zur übrigen Ostslawia umfangreichen Bestand an Demonstrativpronomina dieser Mikrosprache lässt sich der Bogen zu den westslawischen Sprachen spannen, die sich stärker als alle anderen Slawinen in ihrer Mehrzahl durch eine - zumindest

${ }^{22}$ Die Form $t a$ für das slowenische Maskulinum (und auch Femininum) entspricht dem zu erwartenden Reflex von altkirchenslawischem тz, der auch in nordkroatischen Dialekten vertreten ist.

${ }^{23}$ Kordić 1997: 275 spricht von einem viergliedrigen System des Slowenischen, wobei möglicherweise isti, ista, isto zu den Demonstrativa gezählt wurden (dies geschieht etwa bei Bajec/Kolarič/Rupel 1964: 176, wo isti gleichrangig mit ta, tisti und oni angeführt wird).

${ }^{24}$ Ein mit dem Stamm оnъ- gebildetes, distales Pronomen in der Form оный liegt theoretisch zwar auch im Russischen vor, doch ist es mit stark archaischem Charakter behaftet und kommt einzig noch in Redewendungen des Typs во время оно oder во дни оны vor.

${ }^{25}$ Archaizität und stilistische Markierung haftet auch russischem ceŭ an, das in rein pronominaler Bedeutung nur noch in Fügungen wie etwa по сей день, до сих пор Verwendung findet.

${ }^{26}$ Darüber berichtet für das Vojvodina-Rusinische Duličenko (1995: 163). 
nominell - umfassend entwickelte formale Polydeixis auszeichnen. An der Spitze steht dabei das Tschechische, das theoretisch über eine größere Zahl an Demonstrativpronomina als alle anderen slawischen Sprachen verfügt (ten, tento, tamten, onen, tenhle, tenhleten, tamhleten, tuhleten, tadyhleten und tady ten), wobei sogar von einem bis zu zehngliedrigen deiktischen System tschechischer Demonstrativa gesprochen wird. ${ }^{27}$ Hierbei gilt es jedoch zwischen den ein- und zweisilbigen Ausgangsformen ten und onen, den suffigierten, synthetischen Formen und den analytischen Erweiterungen mit tady zu differenzieren, da kombinierten Lautungen ein mehr oder weniger hohes $\mathrm{Maß}$ an stilistischer Markierung innewohnt. ${ }^{28}$ Auf diese Weise erscheint das System des Tschechischen ungeachtet seines Formenreichtums relativ eingeengt und auf die Formen von ten fokussiert zu sein. Vergleichbares trifft auf das Slowakische zu, für das in der Regel auf ten, onen und tento verwiesen wird, wobei den Formen mit on- wie im Tschechischen (aber auch im Slowenischen) stilistisch markierter Charakter zugeschrieben wird. In Bezug auf distales on- sei hier erneut auf das dem Slowakischen benachbarte Rusinische verwiesen, das als einzige ostslawische Sprache mit aнmom über eine eigene aus dem historischen Stamm onz- ererbte Pronominalform (mit Dissimilation im Anlaut) verfügt. Wie auch im Tschechischen besteht im Slowakischen die Möglichkeit einer Verlängerung mit dem Partikel -to, aber auch die Option einer synthetischen Verschmelzung mit den Adverbien $t u$ und tam, sodass deiktische Bezüge nicht nur rein pronominal, sondern auch mit der Hinzuziehung anderer Wortarten ausgedrückt werden können. Formenärmer als Tschechisch und Slowakisch stellt sich das deiktisch zweigliedrige Polnische dar, das über ten, sekundär verlängertes tamten (mit vorangestelltem Lokaladverb) und distales ów verfügt. In den beiden Ausprägungen des Sorbischen zeugen ten und wony (Niedersorbisch) sowie tón und wony (Obersorbisch) von einer Zweigliedrigkeit, die wie in der übrigen Westslawia durch Hinzufügen von Elementen (wie präpositivem $t u$ - und postpositivem -le) semantisch erweitert werden kann. ${ }^{29}$

Summarisch kann zu den Demonstrativpronomina festgehalten werden, dass sich systematische Unterschiede zwischen den Sprachen bzw. den Arealen offenbaren, die von stärker ausgebauten Verweissystemen in der Süd- und Westslawia künden. Dreigliedrige Systeme besitzen neben B/K/M/S auch das Mazedonische und Slowenische, während das Bulgarische eine nur zweifache Gegenüberstellung kennt. Über den formal größten Umfang an Demonstrativlautungen ver-

${ }^{27}$ Dies tut etwa Berger 1994. Die Aufstellung der Pronomina des Tschechischen stammt aus Kordić 1997 (277).

${ }^{28}$ Kordić (1997: 277) verweist in diesem Zusammenhang auf tschechische Grammatiken, denen zufolge bei dieser Pronominalkette einzig ten über neutrale stilistische und deiktische Charakteristiken verfügt.

${ }^{29}$ Bezüglich der Möglichkeit des Anfügens von -le gehen Tschechisch, Slowakisch, Niederund Obersorbisch mit dem Slowenischen konform, dessen historische Verwandtschaft mit den Sprachen der Westslawia unter anderem auch hier erkannt werden kann. 
fügen die westslawischen Sprachen, bei denen jedoch der Formenreichtum mit einer Einengung auf Formen mit dem Stamm tz- einhergeht. Im Rahmen der überwiegend zweideiktischen Ostslawia sei auf das Rusinische verwiesen, das im Unterschied zu Russisch, Ukrainisch und Weißrussisch onz- fortführt und auch noch ein Paradigma mit $s b$ - besitzt.

\section{Zusammenfassendes}

Abschließend sei festgehalten, dass bei den hier behandelten Personal-, Possessiv- und Demonstrativpronomina unterschiedliche Umfänge von Tradition, Innovation und Formenvarianz erkannt werden können. Bezüglich Innovation kann für beinahe alle slawischen Gegenwartssprachen auf den Verlust der DualKategorie verwiesen werden, der bereits im Altkirchenslawischen in manchen pronominalen Klassen nur mehr in eingeschränkter Form erhalten war. Die Personalpronomina mit ihrer - damals wie heute - geringen Formenvarianz zeichnen sich überwiegend durch Bewahrung aus, die sich etwa in der Fortführung des Suppletivismus äußert. Als innovativ stellt sich in allen heutigen Sprachen die „Pronominalisierung“ der Nominativlautungen in der 3. Person dar, die im Altkirchenslawischen primär mit den demonstrativen Elementen ${ }^{*} \mathbf{u}$,

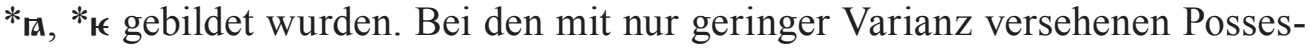
sivpronomina liegt die größte Innovation in der Südslawia vor, in der es zum Ausbau von Paradigmata für die 3. Person kam (njegov, njegova, njegovo ...; nje/zi/n, nje/zi/na, nje/zi/no ...), wogegen die Ost- und Westslawia wie auch das Altkirchenslawische genitivische und kasusneutrale Formen gebrauch(t)en (z. B.: Russisch ezo, ee). Im Unterschied zu Personal- und Possessivpronomina wiesen und weisen die Demonstrativa eine überaus hohe Formenvarianz auf, was im Besonderen auf die an deiktischen Möglichkeiten äußerst reiche älteste slawische Schriftsprache zutrifft. Die Neuerungen der heutigen Sprachen liegen in erster Linie in einem Abbau dieses Systems, wobei vor allem in der Ostslawia die altkirchenslawische Deixis mehrheitlich nicht weitergeführt wird. Im Süden und Westen (insbesondere Tschechisch und Slowakisch) stellen sich die pronominalen Verweismöglichkeiten umfassender und somit zugleich traditioneller dar.

\section{LITERATUR}

Stjepan BABIĆ et al., 2005: Povijesni pregled, glasovi i oblici hrvatskoga književnog jezika. Nacrti za gramatiku. Zagreb: HAZU, Nakladni zavod Globus.

Anton BAJEC, Rudolf KOLARIČ, Mirko RUPEL, 1964: Slovenska slovnica. Ljubljana: Državna založba Slovenije. 
Tilman BERGER, 1994: Wie viele Demonstrativpronomina braucht eine Sprache? Überlegungen zu einigen Merkwürdigkeiten des Tschechischen. Wiener Slawistischer Almanach 33, 21-36.

Aleksandr D. DULIČENKO, 1995: Jugoslavo-Ruthenica. Roboti z ruskej filologiji. Novi Sad: Ruske slovo.

Ivan DURIDANOV, 1991: Gramatika na starobălgarskija ezik. Fonetika - Morfologija - Sintaksis. Sofija: Izdatelstvo na Bălgarskata akademija na naukite.

Alemko GLUHAK, 1993: Hrvatski etimološki rječnik. Zagreb: August Cesarec.

Dževad JAHIĆ, Senahid HALILOVIĆ, Ismail PALIĆ, 2000: Gramatika bosanskoga jezika. Zenica: Dom štampe.

Josip JEDVAJ, 1956: Bednjanski govor. Hrvatski dijalektološki zbornik 1, 279-331.

Janneke KALSBEEK, 1998: The Čakavian Dialect of Orbanići near Žminj in Istria. Amsterdam, Atlanta: Rodopi.

Snježana KORDIĆ, 1997: Predmetne pokazne zamjenice u hrvatskom, poljskom, češkom i ruskom jeziku. Prvi hrvatski slavistički kongres. Zbornik radova I. Ur. Hrvatsko filološko društvo. Zagreb: Hrvatsko filološko društvo. 274-288.

August LESKIEN, 1914: Grammatik der serbo-kroatischen Sprache. Heidelberg: Carl Winter Universitätsverlag.

August LESKIEN, 19557: Handbuch der altbulgarischen (altkirchenslawischen) Sprache. Grammatik - Texte - Glossar. Heidelberg: Carl Winter Universitätsverlag.

Klara E. MAJTINSKAJA, 2009: Mestoimenija v jazykach raznych sistem. Moskva: KD Librokom.

Franz MIKLOSICH, 1926: Vergleichende Grammatik der slavischen Sprache. IV. Band: Syntax. Heidelberg: Carl Winter Universitätsverlag.

Dora SCHULZ, Heinz GRIESBACH, 1978: Grammatik der deutschen Sprache. München: Max Hueber.

Petar SKOK, 1971: Etimologijski rječnik hrvatskoga ili srpskoga jezika. Knjiga prva $(A-J)$, druga $\left(K-\right.$ poni $\left.^{l}\right)$ i treća $\left(\right.$ poni $\left.^{2}-\check{Z}\right)$. Zagreb: Jugoslavenska akademija znanosti i umjetnosti.

Dymytrij SYDOR, 2002: Gramatyka rusyns'koho jazyka. Užhorod: Carpathian Rus.

Arno WONISCH, 2000: Das Variantenparadigma der nicht-genusunterscheidenden Pronomina im Kroatischen. Graz: Phil. DA. 


\section{DIAHRONI IN SINHRONI VIDIKI OSEBNIH, SVOJILNIH IN KAZALNIH ZAIMKOV V SLOVANSKIH JEZIKIH}

V slovanskih jezikih na ravni osebnih, svojilnih in kazalnih zaimkov obstajajo različne stopnje tradicije, inovacije in variantnosti. V skoraj vseh današnjih slovanskih jezikih (z izjemo slovenščine in lužiščine) lahko med inovacijami ugotovimo izgubo dvojine, ki je že v stari cerkveni slovanščini v nekaterih zaimenskih vrstah pokazala prva znamenja razpada. Osebne zaimke - tako danes kot tudi v najstarejšem slovanskem jeziku - odlikuje omejena variantnost oblik in splošna težnja h konservativnosti, kar se med drugim odraža $\mathrm{v}$ ohranjanju supletivizma v sklanjatvah (npr. ja-mene). Inovacijo v vseh današnjih slovanskih jezikih predstavlja pronominalizacija imenovalniških oblik za tretjo osebo, ki so se v stari cerkveni slovanščini oblikovale le s kazalnimi elementi $*_{\mathbf{n}}, *_{\mathbf{r a}}, *_{\mathfrak{r}}$ ali pa tudi s kazalnimi zaimki. Za svojilne zaimke je značilna manjša variantnost, pri čemer je prišlo do največje inovacije $v$ južnoslovanskih jezikih. Tam danes obstaja polna paradigma za tretjo osebo (npr. njegov, njegova, njegovo ...; nje/zi/n, nje/zi/na, nje/zi/no ...), medtem ko vzhodni in zahodni slovanski jeziki (in tudi prvi slovanski knjižni jezik) uporabljajo rodilniške oblike brez razlikovanja sklonov (npr. ezo, $e e v$ ruščini). Za razliko od osebnih in svojilnih zaimkov je za kazalne zaimke značilna precejšnja variantnost oblik, zlasti na ravni bogatega deiktičnega sistema stare cerkvene slovanščine (s splošnimi elementi Trk-, ONł-, oвъ- in cb-). Inovacije $v$ današnjih jezikih se prvenstveno odražajo v izgubi tega sistema, kar predvsem velja za jezike slovanskega vzhoda (npr. эmom, mom v ruščini). Na jugu (zlasti v bosanščini, črnogorščini, hrvaščini, srbščini) in na zahodu (v največji meri v češčini in slovaščini) so možnosti zaimenske deiktike obsežnejše, hkrati pa tudi bolj tradicionalne (npr.: ovaj-taj-onaj v jezikih, ki so nastali iz nekdanje srbohrvaščine). 